
Motrivivência
v. 27 ,
n. 46
p. 15-34,
dezembro/2015

\title{
A PRODUÇÃO CIENTÍFICA SOBRE FUTSAL: análise de dissertações e teses publicadas no portal da Capes entre 1996-2012
}

\author{
André Felipe Caregnato' \\ Thaunnara Szeremeta ${ }^{2}$ \\ Wallinson Ramos Sant Ana da Luz \\ Comile Luciane Silva ${ }^{4}$ \\ Isabelle Costa ${ }^{5}$ \\ Fernando Renato Covichiolli ${ }^{5}$
}

\section{RESUMO}

O presente estudo busca investigar através de uma análise nas dissertações e teses presentes no site do Portal da Capes, o que se aborda no contexto do futsal, bem como destacar os objetivos desses trabalhos, as metodologias, traçar semelhanças, diferenças e possíveis apontamentos para futuras produções. Para a coleta utilizamos o campo de busca Assunto com o termo "Futsal". Foram selecionadas 53 estudos e verificamos predominância das dissertações $(83 \%)$ com relação às teses $(17 \%)$. As pesquisas na sua maioria são de caráter quantitativo (59.3\%) em relação às qualitativas $(34.6 \%)$ e de quantitativa/qualitativa ( $4 \%$ ). São referenciadas como estudo de caso, pesquisa de campo, pesquisa etnográfica, descritivo e quase experimental. Quanto aos procedimentos metodológicos foram usados questionários, entrevistas, observações, filmagens, aplicações de protocolos e testes específicos. Com relação aos assuntos abordados nos trabalhos selecionados, identificamos a maioria deles utilizarem o futsal para tratarem

Doutorando em Educação Física. UFPR, Curitiba/Paraná, Brasil. E-mail: andre.caregnato@hotmail.com

2 Graduação em Educação Física. UFPR, Curitiba/Paraná, Brasil. E-mail: thay_szeremeta@yahoo.com

3 Graduação em Educação Física. UFPR, Curitiba/Paraná, Brasil. E-mail: wallisonsantana@gmail.com

4 Doutoranda em Educação Física. UFPR, Curitiba/Paraná, Brasil. E-mail: camileufpr@yahoo.com.br

5 Graduação em Educação Física. UFPR, Curitiba/Paraná, Brasil. E-mail: belle_ploc@hotmail.com

6 Pós-doutor em Ciências do Desporto e Educação Física. Professor do departamento de Educação Física. UFPR, Curitiba/Paraná, Brasil. E-mail: cavicca@hotmail.com 
de aspectos fisiológicos (30\%) e táticos (19\%) do esporte. Nesse sentido notamos que não há uma preocupação em se estudar determinada assuntos na modalidade pesquisada, por exemplo, nenhuma pesquisa discute o futsal por meio de uma abordagem social deste esporte. Concluímos que essa pode ser considerada uma lacuna no campo acadêmico da modalidade pesquisada e se faz necessário explorá-la.

Palavras-chave: Futsal; Produção Acadêmica; Formação Profissional

\section{INTRODUÇÃO}

Com base em Ferreira (2002), nos últimos anos têm se produzido um conjunto significativo de pesquisas que trazem em comum o desafio de mapear e discutir uma certa produção acadêmica em diferentes campos do conhecimento. A fim de determinar o que se está produzido em determinadas áreas citamos alguns exemplos de trabalhos: Alfabetização no Brasil - o estado do conhecimento (SOARES, 1989); Rumos da pesquisa brasileira em Educação Matemática: o caso da produção científica em cursos de pós-graduação (FIORENTINI, 1994); Tendências da pesquisa acadêmica sobre o ensino de ciências no nível fundamental (MEGID, 1999); Pesquisa em Leitura: um estudo dos resumos e dissertações de mestrado e teses de doutorado defendidas no Brasil, 1980 a 1995 (FERREIRA, 1999); O Estado da Arte da Sociologia do Esporte no Brasil: Um mapeamento da produção bibliográfica de 1997 a 2002 (FERREIRA, 2009).

Nessa perspectiva o presente estudo envolve a modalidade de futsal. Torna se importante pesquisar tal modalidade, uma vez que não há estudos que buscam mapear academicamente a modalidade de futsal, ou seja, o que de fato, se pesquisa com relação a este esporte. Também, é uma das modalidades mais praticadas no Brasil entre crianças e jovens (REZER, 2003;
SANTANA, 1996). Um dos motivos que justifica isso é a expansão das escolinhas de futsal decorrentes do fim dos campos de futebol de várzea (SILVEIRA E STIGGER, 2013; RODRIGUES, 2003). A partir disso, acreditamos ser necessário um olhar sobre o campo acadêmico referente à modalidade, com o intuito de sugerir contribuições para esse campo esportivo.

Para Silveira e Stigger (2013), o futsal se faz tão presente no cenário esportivo do Brasil, devido ao aspecto cultural brasileiro, visto que a modalidade têm semelhanças, estruturais e técnicas, como o futebol de campo. Segundo Santana (2008), o futsal, seguramente, é o esporte coletivo que mais sofreu alterações regulamentares nos últimos anos, com a finalidade de favorecer o espetáculo, tornando um esporte mais atraente, dinâmico, tanto para seus praticantes quanto para o público.

Diante dessas lacunas no conhecimento sobre dissertações e teses no futsal e a fim de contribuir para um futuro direcionamento nos estudos desta modalidade, buscamos analisar as dissertações e teses encontradas no Banco de Teses do Portal da Capes que possuam o termo "Futsal" no título. Em adição, também como propósito da presente revisão, investigamos o que se aborda no contexto do futsal, bem como destacamos os objetivos dos trabalhos analisados, as metodologias, traçamos 
semelhanças, diferenças e possíveis apontamentos para futuras produções.

\section{METODOLOGIA}

O presente estudo caracteriza-se, quanto aos fins, como de caráter qualitativo e descritivo e, quanto aos meios, utiliza-se de pesquisa bibliográfica, definindo-o como um estudo de revisão (GIL, 1995).

\section{a) procedimentos metodológicos:}

A coleta das dissertações e teses aconteceu no Banco de Teses do Portal da Capes. O termo "futsal" foi designado para fazer a seleção dos materiais no campo de busca Assunto do referido portal. Primeiramente, para delinear este artigo, fizemos a coleta dos dados, seleção das dissertações e teses encontradas. Tais dados foram armazenadas em uma planilha do Excel Microsoft Office. Realizamos a análise de todo material selecionado através da leitura centrada principalmente no resumo, introdução, objetivos, metodologias e referências bibliográficas das pesquisas.

A análise dos estudos se deu a partir do ano de 1996, ano que o Portal da Capes começa a disponibilizar as dissertações e teses para consultas. O ano de 2012 é o último ano que no momento da pesquisa, tal portal ofereceu acesso ao material foco deste estudo. Então, para esse artigo faremos a análise dos estudos encontrados de 1996 até o ano de 2012. Vale destacar que até o momento da análise, o Portal de Teses da Capes não disponibilizou os manuscritos do ano de 2010.

Seguindo este critério encontramos 79 dissertações e 17 teses distribuídas a seguir no Quadro 01. b) definição dos critérios de inclusão:

Como este estudo trata em específico da modalidade de futsal, estabelecemos um critério de inclusão para estudarmos as pesquisas que abordam somente tal esporte. Assim, selecionamos para este estudo somente as pesquisas que tivessem no título do trabalho a palavra "futsal".

\section{c) definição dos critérios de exclusão:}

A partir do critério de inclusão, excluímos 35 dissertações e 8 teses, pois as mesmas não apresentavam no título a palavra "futsal". Tal modalidade aparecia somente em algum momento durante estes estudos como, por exemplo, no referencial teórico. Ressaltamos, que a partir da leitura dos trabalhos excluídos e, em uma reunião de consenso entre os autores do estudo, decidimos que de fato, estes não tratam exclusivamente da modalidade futsal.

\section{d) busca e definição dos trabalhos selecio- nados.}

Utilizando como marcador a palavra "futsal" no título, conseguimos trabalhar com as pesquisas que tratam em específico do futsal. Com esse critério obtemos 44 dissertações e 09 teses para serem analisadas neste estudo conforme mostramos nos quadros 02 e 03. Dividimos as tabelas em dissertações e teses, para facilitar a visualização da análise, sendo que cada trabalho foi identificado com um número, também demonstrado nos quadros 02 e 03.

\section{e) Critérios de elaboração das categorias apontadas no quadro 8.}

A partir da leitura do material selecionado foi possível identificarmos os principais assuntos tratados com relação 
ao futsal. Por exemplo, constatamos que alguns trabalhos selecionados envolvem exclusivamente os assuntos técnica, tática, ou pedagogia do esporte. Ocorreram casos que dois assuntos eram evidenciados nos estudos. Para revelar essa análise, definimos, duas categorias apresentadas no quadro 8: assuntos abordados e dissertações / teses.

\section{RESULTADOS}

Quadro 1 - Dissertações e teses encontradas no Banco de Teses do Portal da Capes

\begin{tabular}{|l|c|c|c|c|c|c|c|c|c|c|c|c|c|c|c|c|c|}
\hline & $\mathbf{1 9 9 6}$ & $\mathbf{1 9 9 7}$ & $\mathbf{1 9 9 8}$ & $\mathbf{1 9 9 9}$ & $\mathbf{2 0 0 0}$ & $\mathbf{2 0 0 1}$ & $\mathbf{2 0 0 2}$ & $\mathbf{2 0 0 3}$ & $\mathbf{2 0 0 4}$ & $\mathbf{2 0 0 5}$ & $\mathbf{2 0 0 6}$ & $\mathbf{2 0 0 7}$ & $\mathbf{2 0 0 8}$ & $\mathbf{2 0 0 9}$ & $\mathbf{2 0 1 1}$ & $\mathbf{2 0 1 2}$ & Total \\
\hline Dis. & 1 & 1 & 2 & 3 & 2 & 1 & 5 & 3 & 5 & 6 & 8 & 6 & 6 & 7 & 9 & 14 & 79 \\
\hline Tese & 0 & 0 & 1 & 1 & 0 & 1 & 0 & 1 & 1 & 1 & 1 & 3 & 1 & 0 & 2 & 4 & 17 \\
\hline Total & 1 & 1 & 3 & 4 & 2 & 2 & 5 & 4 & 6 & 7 & 9 & 9 & 7 & 7 & 11 & 18 & 96 \\
\hline
\end{tabular}

Fonte: Banco de Teses da CAPES.

O quadro 1 representa a produção de dissertações e teses quando o termo "futsal" foi designado para fazer a seleção dos materiais no campo de busca Assunto do Portal da Capes. Observamos que a produção sobre o tema futsal foi crescente ao longo dos anos. Enquanto que entre 1996 e 2003 a produção foi reduzida $(22,9 \%$ dos trabalhos), houve um aumento entre os anos de 2004 e $2012(77,1 \%)$, sobretudo nos dois últimos anos pesquisados (2011 e 2012).

Quadro 2 - Autor, título e ano das dissertações encontradas no banco de dados da capes entre 1996 e 2012.

\begin{tabular}{|c|c|l|c|}
\hline & Autor & Título & Ano \\
\hline $\mathbf{1}$ & MOLINA, R. & $\begin{array}{l}\text { Lactato sanguíneo em partida de futsal: Relações com o } \\
\text { condicionamento físico e com o desempenho. }\end{array}$ & 1996 \\
\hline $\mathbf{2}$ & LIMBERGER, O. J. & $\begin{array}{l}\text { Fatores que determinam a distensão muscular e influem } \\
\text { na prática de FUTEBOL SETE e de FUTSAL como lazer, } \\
\text { em Santa Cruz do Sul - RS. }\end{array}$ & 1997 \\
\hline $\mathbf{3}$ & VOZER, R. C. da & $\begin{array}{l}\text { Análise das intervenções pedagógicas em programas de } \\
\text { iniciação ao futsal. }\end{array}$ & 1998 \\
\hline $\mathbf{4}$ & MACHADO, V. M. & $\begin{array}{l}\text { Padrão neurofisiológico de atletas de futsal do Rio Grande } \\
\text { do Sul }\end{array}$ & 1998 \\
\hline $\mathbf{5}$ & PEREIRA, G.V. do & $\begin{array}{l}\text { Seleção de Atletas Adolescentes de 13 a 15 Anos que } \\
\text { Praticam Futsal em Florianópolis: uma Aplicação do } \\
\text { Mcda. }\end{array}$ & 1999 \\
\hline $\mathbf{6}$ & ELY, L. I. & $\begin{array}{l}\text { Configuração do perfil sociocultural dos praticantes de } \\
\text { futsal. }\end{array}$ & 1999 \\
\hline $\mathbf{7}$ & DANTAS, P. M. S. & $\begin{array}{l}\text { Identificação dos Perfis Genético, de Aptidão Física e } \\
\text { Somatotipo que caracterizam Atletas Masculinos, de Alto } \\
\text { Rendimento do Futsal Adulto no Brasil }\end{array}$ & 2001 \\
\hline
\end{tabular}




\begin{tabular}{|c|c|c|c|}
\hline & Autor & Título & Ano \\
\hline 8 & MELO, F. A. T. de & $\begin{array}{l}\text { O futsal como disciplina curricular nos cursos de } \\
\text { graduação em Educação Física, no Distrito Federal }\end{array}$ & 2002 \\
\hline 9 & SAAD, M. A. & $\begin{array}{l}\text { Estruturação das sessões de treinamento técnico-tático nos } \\
\text { escalões de formação do futsal }\end{array}$ & 2002 \\
\hline 10 & SOUZA, P. R. C de & $\begin{array}{l}\text { Processo de validação de teste para avaliar a capacidade } \\
\text { de tomada de decisão e o conhecimento declarativo no } \\
\text { futsal }\end{array}$ & 2002 \\
\hline 11 & REZER, R. & $\begin{array}{l}\text { A prática pedagógica em escolinha de futebol/futsal: } \\
\text { possíveis perspectivas de superação }\end{array}$ & 2003 \\
\hline 12 & COSTA, V. T. da & $\begin{array}{l}\text { Análise do perfil de liderança atual e ideal de treinadores } \\
\text { de futsal de alto rendimento através da Escala de Liderança } \\
\text { no Desporto }\end{array}$ & 2003 \\
\hline 13 & SANTANA, W. C. de & A Pedagogia do Esporte e a Moralidade Infantil. & 2003 \\
\hline 14 & AMORIM, A. C. & $\begin{array}{l}\text { Análise da Percepção de Competência de Crianças de } 11 \\
\text { a } 12 \text { anos praticantes de Futsal }\end{array}$ & 2004 \\
\hline 15 & LEAL JUNIOR, E. C. P. & $\begin{array}{l}\text { Análise dos coeficientes angulares das curvas de } \\
\text { Ventilação Pulmonar e Produção de Dióxido de Carbono } \\
\text { em um teste progressivo com atletas profissionais de } \\
\text { Futebol e Futsal. }\end{array}$ & 2004 \\
\hline 16 & BELLO, M. & $\begin{array}{l}\text { Aplicação da técnica de estabilização rítmica em membros } \\
\text { inferiores para prevenção de lesões musculoesqueléticas } \\
\text { em atletas de futsal. }\end{array}$ & 2005 \\
\hline 17 & BELLO JUNIOR, N. & $\begin{array}{l}\text { Manifestações de inteligência corporal cenestésica na } \\
\text { prática do jogo de futsal: um estudo da categoria principal } \\
\text { masculino. }\end{array}$ & 2005 \\
\hline 18 & PRADO, R. L. do & $\begin{array}{l}\text { Variabilidade da Frequência Cardíaca: Estudo comparativo } \\
\text { das respostas autonômicas cardiovasculares em atletas de } \\
\text { Futsal e sedentários jovens. }\end{array}$ & 2005 \\
\hline 19 & MOREIRA, V. J. P. & $\begin{array}{l}\text { Aquisição do nível de conhecimento tático conforme } \\
\text { os processos metodológicos de ensino-aprendizagem- } \\
\text { treinamento: futsal. }\end{array}$ & 2005 \\
\hline 20 & CARMINATTI, L. J. & $\begin{array}{l}\text { Validade de limiares anaeróbios derivados do teste } \\
\text { incremental de corrida intermitente (tcar) como preditores } \\
\text { do máximo steady- state de lactato em jogadores de futsal. }\end{array}$ & 2006 \\
\hline 21 & BARROS, L. F. P. de & $\begin{array}{l}\text { Limiar de lactato em teste de quadra: validade em } \\
\text { jogadores de futsal. }\end{array}$ & 2006 \\
\hline 22 & BARBIERI, F. A. & $\begin{array}{l}\text { O chute com o membro dominante e não dominante } \\
\text { realizado com a bola parada e em deslocamento no Futsal }\end{array}$ & 2007 \\
\hline 23 & SOARES, J. C. P. & $\begin{array}{l}\text { Efeitos do treinamento de futsal sobre a composição } \\
\text { corporal de escolares }\end{array}$ & 2007 \\
\hline 24 & SILVA, M. V. & $\begin{array}{l}\text { Processo de Ensino-Aprendizagem-Treinamento no Futsal: } \\
\text { Influência no Conhecimento Tático Processual }\end{array}$ & 2007 \\
\hline 25 & GOMES, S. A. & $\begin{array}{l}\text { Tipologia dos esquemas de gênero e os níveis de aptidão } \\
\text { física dos atletas de futsal }\end{array}$ & 2007 \\
\hline 26 & SILVEIRA, R. da & $\begin{array}{l}\text { Esporte, homossexualidade e amizade: estudo etnográfico } \\
\text { sobre o associativismo no futsal feminino }\end{array}$ & 2008 \\
\hline
\end{tabular}




\begin{tabular}{|c|c|c|c|}
\hline & Autor & Título & Ano \\
\hline 27 & LIOTTO, G. J. & $\begin{array}{l}\text { Avaliação funcional de eversores e inversores de tornozelo } \\
\text { em atletas de uma equipe de futsal. }\end{array}$ & 2008 \\
\hline 28 & TENROLLER, C. A. & $\begin{array}{l}\text { Meninas e futsal - um estudo sobre questões de gênero } \\
\text { na Educação Física da escola e para além de seus muros }\end{array}$ & 2009 \\
\hline 29 & BRUN, G. & $\begin{array}{l}\text { Percentuais de frequência cardíaca máxima, consumo } \\
\text { máximo de oxigênio e pico de velocidade em atletas } \\
\text { de futebol e futsal: comparação entre testes de campo e } \\
\text { laboratório }\end{array}$ & 2009 \\
\hline 30 & SAAR, J. F. & $\begin{array}{l}\text { As Estratégias de Comunicação da Liga Futsal } 2008 . \\
\text { Comunicação e Negócios versus Futebol Arte }\end{array}$ & 2009 \\
\hline 31 & TESSER, N. & $\begin{array}{l}\text { Associação entre força, potência, agilidade, velocidade e } \\
\text { massa corporal em atletas profissionais de futsal }\end{array}$ & 2009 \\
\hline 32 & PERFEITO, P. J. C. & $\begin{array}{l}\text { Metodologia de Treinamento no Futebol e Futsal: } \\
\text { Discussão da Tomada de Decisão na Iniciação Esportiva }\end{array}$ & 2009 \\
\hline 33 & TAVARES, B. F. & $\begin{array}{l}\text { Metacognição, Aprendizagem e o Treinamento Tático } \\
\text { Teórico (TTT) do Futsal ‘ }\end{array}$ & 2011 \\
\hline 34 & CRUZ, R. A. R. S. & $\begin{array}{l}\text { Efeitos de Três Programas de Treinamento Sobre Variáveis } \\
\text { Motoras de Escolares Praticantes de Futsal }\end{array}$ & 2011 \\
\hline 35 & GUIMARAES, L. C. & $\begin{array}{l}\text { Perfil de Desenvolvimento das Habilidades Táticas: } \\
\text { Validação Preliminar da Versão para Avaliar Jogadores } \\
\text { de Futsal }\end{array}$ & 2011 \\
\hline 36 & GARCIA, W. F. & $\begin{array}{l}\text { Análise das Capacidades Cognitivas, Emocionais e da } \\
\text { Tomada de Decisão de Atletas de Futsal }\end{array}$ & 2011 \\
\hline 37 & NUNES, R. F. H. & $\begin{array}{l}\text { Índices Físicos e Fisiológicos Associados com Aspectos } \\
\text { Técnicos e Tempo de Jogo como Preditor de Performance } \\
\text { em Atletas de Futsal }\end{array}$ & 2011 \\
\hline 38 & GARCIA, W. F. & $\begin{array}{l}\text { Análise das Cargas de Treinamento e Marcadores de } \\
\text { Estresse em Atletas de Futsal }\end{array}$ & 2011 \\
\hline 39 & FIGUEIRO, M. M. & Ensino-Aprendizagem de Futsal: Uma Abordagem Digital & 2012 \\
\hline 40 & DIAS, B. M. & $\begin{array}{l}\text { Monitoramento da Carga Interna e Respostas Longitudinais } \\
\text { de Marcadores da Carga de Treinamento no Futsal }\end{array}$ & 2012 \\
\hline 41 & FLORIANO, L. T. & $\begin{array}{l}\text { Avaliação Aeróbia em Jogadores de Futsal: Determinação } \\
\text { e Comparação do Vo2 max em Protocolo de Campo } \\
\text { (TCAR) e Laboratório }\end{array}$ & 2012 \\
\hline 42 & DAVID, C. E. B. & $\begin{array}{l}\text { Aspectos Motivacionais e Desempenho Técnico-Tático } \\
\text { em Praticantes de Futsal com } 10 \text { a } 13 \text { anos de Idade }\end{array}$ & 2012 \\
\hline 43 & SILVA, E. da F. R. & $\begin{array}{l}\text { Efeitos da Facilitação Neuromuscular Proprioceptiva e } \\
\text { do Alongamento Estático sobre Contração Voluntária } \\
\text { Máxima e Atividade Eletromiográfica Muscular em } \\
\text { Jogadores de Futsal }\end{array}$ & 2012 \\
\hline 44 & ARCOVERDE, A. S. & $\begin{array}{l}\text { Equilíbrio Estático de Praticantes de Goalball, Futsal e } \\
\text { Não Atletas, Cegos }\end{array}$ & 2012 \\
\hline
\end{tabular}

Fonte: Banco de Teses da CAPES. 
Quadro 3 - Autor, título e ano das teses encontradas no banco de dados da capes entre 1996 e 2012.

\begin{tabular}{|l|c|l|c|}
\hline & Autor & Título & Ano \\
\hline $\mathbf{4 5}$ & FILHO, T.; H. & $\begin{array}{l}\text { Periodização de regimes de treinamentos } \\
\text { antagônicos: um estudo sobre o futsal. }\end{array}$ & 2001 \\
\hline $\mathbf{4 6}$ & DANTAS; P. M. S. & $\begin{array}{l}\text { Relação entre estado e predisposição genética no } \\
\text { futsal brasileiro }\end{array}$ & 2004 \\
\hline $\mathbf{4 7}$ & ARENA; S. S. & $\begin{array}{l}\text { Estudo epidemiológico das lesões esportivas no } \\
\text { basquetebol, futsal e voleibol ocorridas em atletas } \\
\text { jovens. }\end{array}$ & 2005 \\
\hline $\mathbf{4 8}$ & RÉ; A. H. N. & $\begin{array}{l}\text { Desempenho de adolescentes no futsal: relações } \\
\text { com medidas antropométricas, motoras e tempo } \\
\text { de prática. }\end{array}$ & 2007 \\
\hline $\mathbf{4 9}$ & SANTANA, W. C. de & $\begin{array}{l}\text { A Visão Estratégico-Tática de Técnicos Campeões } \\
\text { da Liga Nacional de Futsal. }\end{array}$ & 2008 \\
\hline $\mathbf{5 1}$ & JUNIOR, A. S. da M. & $\begin{array}{l}\text { A noção de Espaço na Prática Desportiva: } \\
\text { um Estudo de Casos Múltiplos com Base na } \\
\text { Epistemologia Genética com Praticantes de Futsal }\end{array}$ & 2011 \\
\hline $\mathbf{5 3}$ & SAQUIN, A. & $\begin{array}{l}\text { O Calçado Esportivo Destinado à Prática de } \\
\text { Futsal: Avaliação Mecânica, Biomecânicas e de } \\
\text { Percepção }\end{array}$ & 2012 \\
\hline
\end{tabular}

Fonte: Banco de Teses da CAPES.

Dos 53 trabalhos analisados houve uma predominância de dissertações (83\%) em relação a teses $(17 \%)$. Entre os autores que produziram dissertações no período pesquisado, somente três deles (5.3\%) concluíram suas teses até 2012 tendo o futsal como objeto de estudo: Dantas (2004); Santana (2008) e Saad (2012). Os outros autores de teses ou não tiveram o futsal como objeto de estudo em suas dissertações, ou concluíram o mestrado acadêmico antes de 1996. 
Quadro 4 - Tipo de pesquisa e metodologia empregada nas dissertações sobre futsal

\begin{tabular}{|c|c|c|}
\hline & Tipo de pesquisa & Metodologia \\
\hline 1 & Não encontrado & Não encontrado \\
\hline 2 & Qualitativa & $\begin{array}{l}\text { Questionários para com questões abertas. Observações. Análise do } \\
\text { Conteúdo }\end{array}$ \\
\hline 3 & Qualitativa & $\begin{array}{l}\text { Descritivo Exploratório, } \\
\text { Foram utilizados para a coleta de dados três locais previamente } \\
\text { definidos: um Clube Social; um Projeto de Extensão e uma Escolinha } \\
\text { Particular. } \\
\text { Entrevistas, Observações, Filmagens. }\end{array}$ \\
\hline 4 & Quantitativa & $\begin{array}{l}\text { Pesquisa com atletas de } 5 \text { equipes profissionais. } \\
\text { Questionário de STRELAU (1984). }\end{array}$ \\
\hline 5 & Qualitativa & Metodologia de multicritério de apoio à decisão (MCDA). \\
\hline 6 & Qualitativa & Pesquisa de campo, Questionários e Observações. \\
\hline 7 & Quantitativa & $\begin{array}{l}\text { Método descritivo, com tipologia de perfil e delineamento, quase- } \\
\text { experimental, } \\
\text { Protocolos: Método dermatoglífico; o Somatotípico; os de aptidão física, } \\
\text { específicos, para medidas, de rendimento esportivo. }\end{array}$ \\
\hline 8 & Qualitativa & Pesquisa de campo, entrevistas e questionários \\
\hline 9 & Qualitativa & $\begin{array}{l}\text { Descritivo Exploratório, observação sistemática e direta, filmagem de } \\
\text { treinos. }\end{array}$ \\
\hline 10 & Qualitativa & $\begin{array}{l}92 \text { cenas de situações de ataque no futsal foram elaboradas, filmadas e } \\
\text { posteriormente editadas numa fita de vídeo de forma padronizada. } 10 \\
\text { técnicos de futsal julgaram as ações. Análise descritiva }\end{array}$ \\
\hline 11 & Qualitativa & $\begin{array}{l}\text { Natureza descritivo-exploratória, } \\
02 \text { escolinhas de futebol e } 04 \text { de futsal com alunos entre } 06 \text { e } 10 \text { anos, } \\
\text { Questionário de Perfil; Entrevista Semiestruturada; Observação. }\end{array}$ \\
\hline 12 & Quantitativa & $\begin{array}{l}\text { O instrumento utilizado foi a ELD (versões perfil atual e ideal), composta } \\
\text { por } 40 \text { situações que envolvem o componente da liderança. Aplicação } \\
\text { de Questionário de dados demográficos. }\end{array}$ \\
\hline 13 & Qualitativa & $\begin{array}{l}\text { Observação em escolas especializadas de dois clubes esportivos e de } \\
\text { duas associações congêneres. } \\
\text { Utilizou-se como técnica de coleta de dados a observação não- } \\
\text { participante e filmagem de aulas. }\end{array}$ \\
\hline 14 & Quantitativa & Questionário. Estatística Descritiva (pacote estatístico SPSS). \\
\hline 15 & Quantitativa & $\begin{array}{l}\text { Protocolo de avaliação cardiorrespiratória. } \\
\text { Tratamento matemático com os dados. }\end{array}$ \\
\hline 16 & Quantitativa & Aplicação da técnica de estabilização rítmica em membros inferiores. \\
\hline 17 & Qualitativa & Filmagens, observações e entrevistas em atletas adultos de futsal. \\
\hline 18 & Quantitativa & $\begin{array}{l}\text { Protocolos de avaliação clínica e antropométrica; teste de esforço físico } \\
\text { dinâmico contínuo do tipo degraus (TEFDC-D); ergo espirometria e } \\
\text { eletrocardiografia dinâmica, (ECG). }\end{array}$ \\
\hline 19 & Quantitativa & $\begin{array}{l}\text { O estudo do processo cognitivo com base no Modelo de Greco (1999). } \\
\text { Filmagem de treinos e aplicação dos testes de conhecimento tático } \\
\text { processual KORA. (Avaliação Orientada através do Conceito). }\end{array}$ \\
\hline
\end{tabular}




\begin{tabular}{|c|c|c|}
\hline & Tipo de pesquisa & Metodologia \\
\hline 20 & Quantitativa & $\begin{array}{l}\text { Teste incremental em esforço contínuo, corrida intermitente, teste de } \\
\text { carga constante. Realizados em } 08 \text { jogadores de futsal adultos. }\end{array}$ \\
\hline 21 & Quantitativa & $\begin{array}{l}\text { Teste incremental em esteira (protocolo de Heck, 1985), teste } \\
\text { progressivo em esteira, corrida intermitente de 20m. }\end{array}$ \\
\hline 22 & Quantitativa & Método de Euler. Analise Biomecânica. \\
\hline 23 & Quantitativa & Protocolo de avaliações de massa corporal, estatura e dobras cutâneas. \\
\hline 24 & Quantitativa & $\begin{array}{l}\text { Protocolo de Stefanello (1999), filmagem de treinos. Aplicação do teste } \\
\text { KORA (Avaliação Orientada através do Conceito) }\end{array}$ \\
\hline 25 & Quantitativa & $\begin{array}{l}\text { Aplicação da técnica da antropometria para mensurar a composição } \\
\text { corporal e os testes Squat Jump e Counter Movement Jump e Running } \\
\text { Anaerobic Sprint Test para força e potência. } \\
\text { Análises de Variância (ANOVA) do tipo One Way e Análises de } \\
\text { Variância Multivariadas (MANOVA). }\end{array}$ \\
\hline 26 & Qualitativa & $\begin{array}{l}\text { Investigação etnográfica em um time de futsal feminino da cidade de } \\
\text { Porto Alegre. Pesquisa de campo e entrevistas. }\end{array}$ \\
\hline 27 & Quantitativa & Estudo de caso. Análise de duas variáveis (torque e ativação) \\
\hline 28 & Qualitativa & $\begin{array}{l}\text { Análise de artefatos culturais: jornais (Diário de Canoas), revistas, livros } \\
\text { didáticos de futsal. Entrevistas e questionários. }\end{array}$ \\
\hline 29 & Quantitativa & Testes incrementais máximos em esteiras rolantes. \\
\hline 30 & & Entrevistas. \\
\hline 31 & Quantitativa & $\begin{array}{l}\text { Teste de corrida de } 30 \mathrm{~m} \text { (T30), teste de agilidade de SEMO, teste de } \\
\text { uma repetição máxima do exercício meio agachamento }(1 \mathrm{RM}) \text { e teste } \\
\text { de salto vertical Counter Movement Jump }(\mathrm{CMJ}) \text {. Aplicou-se o teste de } \\
\text { Correlação de Pearson }(\mathrm{p}<0,05) \text { para verificar a correlação entre as } \\
\text { variáveis estudadas. }\end{array}$ \\
\hline 32 & Qualitativa & $\begin{array}{l}\text { Articulação de três métodos de ensino-aprendizagem-treinamento: } \\
\text { método de ensino centrado nos Jogos Condicionados, Situacional, } \\
\text { Formativo Conceitual. }\end{array}$ \\
\hline 33 & Qualitativa & Análise de vídeo \\
\hline 34 & Quantitativa & $\begin{array}{l}\text { Avaliações Antopométricas; corrida de } 20 \text { metros; salto horizontal; } \\
\text { Illinois Agility Test; Yo-yo endurence Test; RAST; Correção Linear de } \\
\text { Pearson }\end{array}$ \\
\hline 35 & Não encontrada & $\begin{array}{l}\text { Os itens foram submetidos ao julgamento de } 10 \text { juízes que } \\
\text { avaliaram quatro critérios: clareza da linguagem, pertinência prática, } \\
\text { representatividade e precisão dos itens. Aplicação de teste piloto }\end{array}$ \\
\hline 36 & $\begin{array}{l}\text { Qualitativa/ } \\
\text { Quantitativa }\end{array}$ & $\begin{array}{l}\text { Protocolo de Avaliação do Conhecimento Declarativo no Futebol; } \\
\text { Questionário de Estilo de Tomada de Decisão no Esporte; entrevista } \\
\text { semiestruturada. Análise de conteúdo do tipo categorial, Qui- } \\
\text { Quadrado, Regressão de Poisson com ajuste robusto de variância, Teste } \\
\text { de Homogeneidade das variâncias, ANOVA, teste de Tukey, teste Box's } \\
\text { M Test e MANOVA. }\end{array}$ \\
\hline 37 & Quantitativa & $\begin{array}{l}\text { Avaliação antropométrica; teste incremental na esteira; teste de força } \\
\text { isocinética; testes de sprint de 5, } 15 \text { e } 30 \text { m e capacidade de sprint } \\
\text { repetido (CSR). Correlação de Person; Stepwise; Teste T. }\end{array}$ \\
\hline 38 & Não encontrada & Não encontrada \\
\hline
\end{tabular}




\begin{tabular}{|c|c|l|}
\hline & Tipo de pesquisa & Metodologia \\
\hline $\mathbf{3 9}$ & Não encontrada & Não encontrada \\
\hline $\mathbf{4 0}$ & Quantitativa & $\begin{array}{l}\text { PSE da sessão, Marcadores bioquímicos creatinaquinase (CK), lactato } \\
\text { desidrogenase (LDH), } \mathrm{n}^{\circ} \text { de hemácias, hemoglobina e hematócrito; } \\
\text { marcadores imunológicos } \mathrm{n}^{\circ} \text { de leucócitos, neutrófilos e de linfócitos; } \\
\text { RESTQ-76 SPORT }\end{array}$ \\
\hline $\mathbf{4 1}$ & Quantitativa & Teste incremental intermitente de campo (T-CAR) \\
\hline $\mathbf{4 2}$ & Quantitativa & $\begin{array}{l}\text { Questionário de motivação esportiva (GAYA; CARDOSO, 1998); } \\
\text { GPAI - Game Performance Assessment Instrument (OSLIN; MITCHEL; } \\
\text { GRIFFIN, 1998) }\end{array}$ \\
\hline $\mathbf{4 3}$ & Quantitativa & $\begin{array}{l}\text { Sessões experimentais diferentes em dias não consecutivos separados } \\
\text { por 72 h em ordem randomizada: AE, FNP e sessão sem alongamento } \\
\text { (SC). }\end{array}$ \\
\hline $\mathbf{4 4}$ & Quantitativa & $\begin{array}{l}\text { Plataforma de força CEFISE, a qual mediu as variações posturais nas } \\
\text { posições Bipodal e Semi Tandem; Estatística descritiva }\end{array}$ \\
\hline
\end{tabular}

Fonte: Banco de Teses da CAPES.

Quadro 5 - Tipo de pesquisa e metodologia empregada nas teses sobre futsal

\begin{tabular}{|l|l|l|}
\hline $\mathbf{4 5}$ & Tipo de pesquisa & Metodologia \\
\hline $\mathbf{4 6}$ & Quantitativa & $\begin{array}{l}\text { Bateria de testes e medidas antropométricas. Aplicação de testes } \\
\text { motores de força rápida, agilidade, potência aeróbia e resistência } \\
\text { aeróbia. }\end{array}$ \\
\hline $\mathbf{4 7}$ & Quantitativa & $\begin{array}{l}\text { Protocolos: de Dermatoglifia (CUMMINS \& MIDLO 1942), Jump } \\
\text { Test, Shuttle run, Mor-Cristian, de habilidades e destrezas gerais } \\
\text { no futebol, Multitage Fitness Test, YO-YO Teste de Recuperação } \\
\text { Intermitente, Método Somatotipológico, de Health \& Carter. } \\
\text { Estatística descritiva, normalidade e comparação. }\end{array}$ \\
\hline $\mathbf{4 8}$ & Quantitativa & $\begin{array}{l}\text { Aplicação de Questionário de lesão esportiva. Entrevista estruturada. } \\
\text { Análise estatística descritiva de frequência e percentagem (\%) do } \\
\text { número de lesões, e } \\
\text { análise comparativa com o teste do qui-quadrado. }\end{array}$ \\
\hline $\mathbf{4 9}$ & Qualitativa & $\begin{array}{l}\text { Medidas Massa Corporal, estatura, dobras cutâneas, comprimento } \\
\text { de membros inferiores e indicadores de habilidades motoras obtidos } \\
\text { fora da situação de jogo, tempo de prática dedicado à modalidade } \\
\text { e desempenho técnico em situação real de jogo. Análise descritiva. }\end{array}$ \\
\hline $\mathbf{5 0}$ & Qualitativa & $\begin{array}{l}\text { Entrevistas semiestruturadas, Questionários. Técnica do Discurso do } \\
\text { Sujeito Coletivo. }\end{array}$ \\
\hline $\mathbf{5 1}$ & Estudo de casos múltiplos \\
\hline $\mathbf{5 2}$ & Qualitatival & $\begin{array}{l}\text { Massa, resistência e dureza do calçado; temperatura de aquecimento } \\
\text { do pé; variação da radiação térmica do calçado; pressão plantar; } \\
\text { força de reação do solo (plataforma de força AMTI) e percepção do } \\
\text { usuário (escala visual). }\end{array}$ \\
\hline $\mathbf{5 3}$ & Quantitativa & $\begin{array}{l}\text { Estatística descritiva (média, desvio padrão, soma, frequência } \\
\text { absoluta e frequência relativa), teste Kolmogorov-Smirnov, teste t } \\
\text { pareado e teste t para amostras independentes }\end{array}$ \\
\hline
\end{tabular}

Fonte: Banco de Teses da CAPES. 
Nos trabalhos que conseguimos identificar as metodologias utilizadas, observamos a predominância de pesquisas com o caráter quantitativo $(59.3 \%)$ em relação às qualitativas $(36.7 \%)$ e de quantitativa / qualitativa $(4 \%)$. Vale destacar que em quatro trabalhos não foi possível determinar o tipo de metodologia utilizada, uma vez que os mesmos não forneciam maiores detalhes sobre os procedimentos metodológicos utilizados.

Para identificarmos os assuntos abordados no futsal e apresentados no quadro abaixo os objetivos encontrados nos trabalhos selecionados. Pensamos que isso nos auxilia na compreensão de quais são os assuntos principais destes estudos.

Quadro 6 - Objetivos principais das dissertações selecionadas

\begin{tabular}{|c|c|}
\hline & Objetivos \\
\hline 1 & $\begin{array}{l}\text { Caracterizar o perfil dos deslocamentos e da condição física dos atletas de futsal, e as relações } \\
\text { com o lactato sanguíneo de partida. }\end{array}$ \\
\hline 2 & $\begin{array}{l}\text { Analisar a preparação física ideal preconizada, com a usual praticada no futebol sete e futsal, } \\
\text { por lazer. }\end{array}$ \\
\hline 3 & $\begin{array}{l}\text { Verificar, analisar e interpretar as intervenções pedagógicas utilizadas pelo professor nos } \\
\text { Programas de Iniciação ao Futsal. }\end{array}$ \\
\hline 4 & $\begin{array}{l}\text { Verificar se as peculiaridades tipológicas do sistema nervoso dos atletas de futsal devem ser } \\
\text { diferentes dos atletas com diferentes níveis de performance esportiva. }\end{array}$ \\
\hline 5 & $\begin{array}{l}\text { Propor um modelo para seleção de atletas adolescentes com idade de } 13 \text { a } 15 \text { anos, que } \\
\text { praticam futsal em Florianópolis, utilizando a metodologia de multicritério de apoio à } \\
\text { decisão (MCDA). }\end{array}$ \\
\hline 6 & $\begin{array}{l}\text { Configurar o perfil dos praticantes de futsal de participação, identificando indicadores para } \\
\text { essa prática esportiva. }\end{array}$ \\
\hline 7 & $\begin{array}{l}\text { Caracterizar atletas masculinos, de alto rendimento, participantes do futsal adulto, no Brasil, } \\
\text { identificando o perfil genético, de aptidão física e somatotípico. }\end{array}$ \\
\hline 8 & $\begin{array}{l}\text { Identificar as razões atribuídas à ausência do futsal no currículo, bem como as implicações } \\
\text { que essa lacuna na formação acadêmica estaria acarretando à atuação do professor de } \\
\text { educação física. }\end{array}$ \\
\hline 9 & $\begin{array}{l}\text { Analisar os procedimentos adotados por treinadores de Futsal de base para transformar } \\
\text { objetivos e conteúdos em atividades e tarefas de treinamento técnico-tático. }\end{array}$ \\
\hline 10 & $\begin{array}{l}\text { Construir e validar teoricamente um teste que avalie o nível de rendimento da capacidade } \\
\text { de tomada de decisão tática e o nível de conhecimento declarativo em situações de ataque } \\
\text { no futsal. }\end{array}$ \\
\hline 11 & $\begin{array}{l}\text { Investigar a prática pedagógica no âmbito das escolinhas de futebol/futsal, apontando para } \\
\text { princípios norteadores de procedimentos metodológicos e pedagógicos que possam servir } \\
\text { de pressupostos superadores. }\end{array}$ \\
\hline 12 & $\begin{array}{l}\text { Verificar a consistência interna da Escala de Liderança no Desporto (ELD) na língua } \\
\text { portuguesa brasileira; comparar a percepção do técnico em relação ao seu comportamento } \\
\text { (perfil atual) e a um comportamento modelo ou desejado (perfil ideal); avaliar se existe um } \\
\text { estilo de liderança (interação e decisão) preferencial por parte dos treinadores de futsal; } \\
\text { averiguar se o nível de experiência pode influenciar no perfil de liderança do técnico. }\end{array}$ \\
\hline
\end{tabular}




\begin{tabular}{|c|c|}
\hline & bjetivos \\
\hline 13 & $\begin{array}{l}\text { Descobrir quais os tipos de relações estabelecidas em aulas de futsal na infância e em } \\
\text { particular se a pedagogia do esporte praticada neste cenário educa para a heteronomia ou } \\
\text { para a autonomia. }\end{array}$ \\
\hline 14 & $\begin{array}{l}\text { Investigar a percepção de competência de crianças de } 11 \text { e } 12 \text { anos praticantes de futsal na } \\
\text { cidade de Maringá, tendo como suporte a teoria de Harter. }\end{array}$ \\
\hline 15 & $\begin{array}{l}\text { Realizar uma análise do comportamento das curvas de Ventilação Pulmonar (VE), Consumo } \\
\text { de Oxigênio (VO2) e Produção de Dióxido de Carbono (VCO2) antes e depois do Limiar } \\
\text { Anaeróbio (LA). }\end{array}$ \\
\hline 16 & $\begin{array}{l}\text { Aplicar a técnica de ER para membros inferiores em atletas de futsal a fim de verificar se esta } \\
\text { técnica previne lesões musculoesqueléticas, comparados a técnica de alongamento passivo. }\end{array}$ \\
\hline 17 & $\begin{array}{l}\text { Identificar manifestações de inteligência corporal cinestésica expressadas na prática dos } \\
\text { jogos de futsal por atletas da categoria principal masculino de um determinado clube, por } \\
\text { meio de filmagens, observações e entrevistas. }\end{array}$ \\
\hline 18 & $\begin{array}{l}\text { Estudar a variabilidade da frequência cardíaca (VFC) no domínio do tempo (DT) e no domínio } \\
\text { da frequência (DF) em atletas praticantes de atividade física do tipo futebol de salão (AFS). }\end{array}$ \\
\hline 19 & $\begin{array}{l}\text { Observar como se procede ao E-A-T técnico-tático no Futsal através dos métodos de E-A-T } \\
\text { aplicados pelos treinadores e quais os resultados deste processo para os praticantes, no nível } \\
\text { de rendimento do conhecimento tático processual; e verificar se há diferença no nível de } \\
\text { conhecimento tático processual em praticantes de futsal. }\end{array}$ \\
\hline 20 & $\begin{array}{l}\text { Verificar a validade do Limiar Anaeróbio (Lan) como preditores do máximo steady-state de } \\
\text { lactato (MSSL), na modalidade de Futsal. }\end{array}$ \\
\hline 21 & $\begin{array}{l}\text { O objetivo deste estudo foi a validação da medida de limiar anaeróbio com o teste escalonado } \\
\text { intermitente de } 20 \text { m de ida-e-volta em quadra, comparando-o com teste escalonado em } \\
\text { esteira e com o máximo "steady-state" de lactato (MLSS) em teste retangular simulado, em } \\
\text { jogadores de Futsal. }\end{array}$ \\
\hline 22 & $\begin{array}{l}\text { Descrever o chute executado com o membro dominante e com o membro não dominante } \\
\text { realizado com a bola parada e em deslocamento no futsal. }\end{array}$ \\
\hline 23 & $\begin{array}{l}\text { a área do nordeste (Parnaíba-PI) e } \\
\text { osição corporal em escolares }\end{array}$ \\
\hline 24 & $\begin{array}{l}\text { Observar quais os métodos de ensino-aprendizagem-treinamento (E-A-T) técnico-tático } \\
\text { aplicados por treinadores de futsal em Belo Horizonte e; verificar qual a influência desses } \\
\text { métodos no nível de conhecimento tático processual (CTP) dos atletas. }\end{array}$ \\
\hline 25 & $\begin{array}{l}\text { Avaliar se atletas de futsal que diferem quanto à tipologia dos esquemas de gênero apresentam } \\
\text { diferenças na composição corporal e nos níveis de aptidão física. }\end{array}$ \\
\hline 26 & Discutir o associativismo esportivo de mulheres em esportes que são ditos masculinos \\
\hline 27 & $\begin{array}{l}\text { Avaliar as razões de toque e ativação, bem como a potência e a o trabalho musculares } \\
\text { realizados pela musculatura eversora e inversora do tornozelo em atletas de uma equipe de } \\
\text { futsal. }\end{array}$ \\
\hline 28 & $\begin{array}{l}\text { nalisar os discursos que compõem determinados regimes de verdade sobre a presença- } \\
\text { usência de mulheres/meninas na prática de futsal. }\end{array}$ \\
\hline 29 & $\begin{array}{l}\text { Analisar as relações entre \% FC máxima, \%VO2max e \%PV em jogadores de equipes } \\
\text { profissionais de futebol e futsal durante testes incrementais em esteira rolante e campo. }\end{array}$ \\
\hline 30 & $\begin{array}{l}\text { Mostrar quais são as ações de comunicação e marketing da Liga Futsal e verificar se estão } \\
\text { sendo bem administradas pela Confederação e/ou empresas especializadas. Pretende-se, } \\
\text { também, analisar como a comunicação pode transformar-se em ferramenta útil na divulgação } \\
\text { dos clubes de futebol de salão e da Liga Futsal. }\end{array}$ \\
\hline
\end{tabular}




\begin{tabular}{|c|c|}
\hline & bjetivos \\
\hline 31 & $\begin{array}{l}\text { רvestigar as relações entre as qualidades físicas velocidade, agilidade, força, potência e a } \\
\text { hassa corporal em atletas profissionais de futsal. }\end{array}$ \\
\hline 32 & $\begin{array}{l}\text { iscutir a sistematização, aplicação e a avaliação de uma metodologia de treinamento com } \\
\text { co no desenvolvimento das ações táticas do futebol e futsal. }\end{array}$ \\
\hline 33 & $\begin{array}{l}\text { Investigar a correlação entre meta cognição e desempenho no treinamento tático-teórico } \\
\text { (TTT) de Futsal e a possibilidade da utilização da meta cognição como ferramenta para o } \\
\text { TTT de Futsal. }\end{array}$ \\
\hline 34 & $\begin{array}{l}\text { Observar o desenvolvimento das capacidades motoras de atletas juvenis } \\
\text { de futsal submetidos a três programas de treinamento durante um período de } 16 \text { semanas, } \\
\text { sendo um programa baseado na Teoria Clássica do Treinamento Desportivo, outro } \\
\text { programa baseado no treinamento por Cargas Seletivas com Treinamento Integrado, e } \\
\text { outro baseado apenas no jogo }\end{array}$ \\
\hline 35 & $\begin{array}{l}\text { Adaptar e validar teoricamente um instrumento para avaliar as habilidades táticas em } \\
\text { jogadores de futsal em quatro situações: no ataque com a posse da bola; no ataque sem a } \\
\text { posse da bola; marcando o adversário com a posse da bola; e marcando o adversário sem a } \\
\text { posse da bola. }\end{array}$ \\
\hline 36 & $\begin{array}{l}\text { Analisar as capacidades cognitivas e emocionais em relação à tomada de decisão de } \\
\text { jogadores de futsal do estado do Paraná. }\end{array}$ \\
\hline 37 & $\begin{array}{l}\text { orrelacionar os indicadores fisiológicos e físicos com os aspectos técnicos e o tempo de } \\
\text { go em atletas de elite de futsal }\end{array}$ \\
\hline 38 & $\begin{array}{l}\text { Descrever o padrão de distribuição da intensidade de treinamento das sessões, verificar a } \\
\text { associação entre os métodos de quantificação de CT baseados na percepção subjetiva de } \\
\text { esforço (PSE da sessão) e na frequência cardíaca (FC) proposto por Lucia et al., (1) (Lucia } \\
\text { TRIMP), verificar a influência da potência aeróbia (VO2max) sobre a carga interna de } \\
\text { treinamento e avaliar o efeito das CT sobre parâmetros de imunidade da mucosa oral e de } \\
\text { sintomas de estresse no futsal. }\end{array}$ \\
\hline 39 & $\begin{array}{l}\text { Desenvolver um objeto de aprendizagem digital voltado para o ensino de futsal em nível } \\
\text { escolar e não escolar, através da utilização de alguns conceitos de futsal }\end{array}$ \\
\hline 40 & $\begin{array}{l}\text { Descrever e analisar a dinâmica da carga interna de treinamento em um macro ciclo de futsal } \\
\text { de alto rendimento }\end{array}$ \\
\hline 41 & $\begin{array}{l}\text { Determinar e comparar o consumo máximo de oxigênio obtido em protocolo de campo } \\
\text { (T-CAR) e laboratório }\end{array}$ \\
\hline 42 & $\begin{array}{l}\text { Analisar a associação entre motivação esportiva e desempenho técnico-tático de praticantes } \\
\text { de futsal com idade de } 10 \text { a } 13 \text { anos nos clubes da cidade de Pelotas }\end{array}$ \\
\hline 43 & $\begin{array}{l}\text { Investigar e comparar os efeitos da FNP e do AE sobre a contração voluntária máxima (CVM) } \\
\text { e ativação muscular em jogadores de futsal, bem como em indivíduos sedentários }\end{array}$ \\
\hline 44 & o estático entre cegos praticantes de goalball, futsal e não atletas \\
\hline
\end{tabular}

Fonte: Banco de Teses da CAPES. 
Quadro 7 - Objetivos das teses selecionadas

\begin{tabular}{|c|c|}
\hline & bjetivo \\
\hline 45 & $\begin{array}{l}\text { Descrever os efeitos da periodização de regimes de treinamentos antagônicos sobre os } \\
\text { resultados de testes motores e sobre o desempenho em quadra, este estudo teve como } \\
\text { sujeitos dez jogadores de futsal, que se submeteram a uma bateria de testes e medidas } \\
\text { antropométricas em diferentes momentos do período preparatório e competitivo do } \\
\text { Campeonato Estadual de Futsal - Série Ouro, RS, realização durante o ano de } 2000 \text {. }\end{array}$ \\
\hline 46 & $\begin{array}{l}\text { Averiguar a relação entre estado e potencial genético, baseada na Dermatoglifia, no } \\
\text { somatotipo e nas qualidades físicas básicas, em diferentes níveis de qualificação esportiva, } \\
\text { e o desenvolvimento de um modelo capaz de demonstrar o potencial genético para a } \\
\text { performance esportiva, no futsal. }\end{array}$ \\
\hline 47 & $\begin{array}{l}\text { Verificar a incidência das principais lesões esportivas comuns em atletas jovens de } 16 \text { a } \\
19 \text { anos de idade, que participaram de treinamento regular ou federado no ano de 2002, } \\
\text { nas modalidades esportivas basquetebol, futsal e voleibol. }\end{array}$ \\
\hline 48 & $\begin{array}{l}\text { Comparar jogadores adolescentes de futsal de diferentes categorias competitivas e } \\
\text { também titulares e reservas das mesmas categorias, em características antropométricas, } \\
\text { motoras, indicadores do tempo de prática e desempenho técnico em situação real de jogo } \\
\text { e verificar as relações entre essas variáveis. }\end{array}$ \\
\hline 49 & $\begin{array}{l}\text { Descortinar a visão de técnicos campeões da Liga Futsal brasileira acerca dos } \\
\text { comportamentos estratégico-táticos mais eficazes de serem postos em prática nas } \\
\text { diferentes fases do jogo e, ainda, a que desenhos metodológicos, habitualmente, recorrem } \\
\text { para ensiná-los, o que configuraria a sua inclinação metodológica. }\end{array}$ \\
\hline 50 & $\begin{array}{l}\text { Avaliar possíveis influências da constituição da noção de espaço no sujeito, entendida de } \\
\text { acordo com a Epistemologia Genética de Jean Piaget, na aprendizagem e desenvolvimento } \\
\text { da prática de futsal. }\end{array}$ \\
\hline 51 & Investigar o calçado de futsal em seus parâmetros mecânicos, biomecânicos e perceptivos \\
\hline 52 & $\begin{array}{l}\text { Analisar as estratégias construídas por jovens atletas de futsal feminino de Santa Catarina, } \\
\text { para conciliarem a formação esportiva e a formação escolar, descrevendo seu perfil escolar } \\
\text { e expectativas de formação acadêmica, bem como entender o significado atribuído ao } \\
\text { treino, aos estudos e à escola }\end{array}$ \\
\hline 53 & $\begin{array}{l}\text { Analisar o processo de ensino-aprendizagem-treinamento técnico-tático dos jogadores } \\
\text { de futsal nas categorias sub-13 e sub-15 em Santa Catarina considerando as metodologias } \\
\text { de ensino, o nível de desempenho individual e a experiência esportiva }\end{array}$ \\
\hline
\end{tabular}

Fonte: Banco de Teses da CAPES. 
Quadro 8 - Principais categorias abordadas em teses e dissertações sobre futsal.

\begin{tabular}{|l|l|}
\hline & \\
\hline Aspectos fisiológicos & $1,4,15,18,20,21,24,25,29,31,37,38,41,43,44,45$ \\
\hline Tática & $9,10,17,19,24,32,33,35,36,42,48,52$ \\
\hline Pedagogia do Esporte & $3,9,11,13,14,32,39,48,49,50,52,53$ \\
\hline Preparação física & $1,2,16,23,27,37,38,40,41,45$ \\
\hline Técnica & $9,19,24,37,42,47,52$ \\
\hline Aspectos motivacionais & $12,36,42,51$, \\
\hline Gênero & $25,26,28,51$ \\
\hline Biomecânica & $22,44,51$ \\
\hline Capacidades motoras & $31,34,47$, \\
\hline Genética & $7,46,49$ \\
\hline Perfil dos praticantes de futsal & $6,7,12$ \\
\hline Lesões Esportivas & 16,47 \\
\hline Marketing esportivo & 30 \\
\hline $\begin{array}{l}\text { Disciplina futsal no curso de } \\
\text { Educação Física }\end{array}$ & 8 \\
\hline Seleção de atletas & 5 \\
\hline
\end{tabular}

Fonte: Elaboração própria dos autores. 2012.

Os trabalhos que têm como assunto principal os aspectos fisiológicos são dominantes entre as demais, com 16 trabalhos tratando este tema. Aspectos táticos, a pedagogia do esporte, preparação física e a técnica vêm em seguida; os dois primeiros com 12 trabalhos cada, e os demais com 10 e 7 respectivamente. Por outro lado, o marketing esportivo, o futsal enquanto disciplina acadêmica e a seleção de atletas apareceram em apenas um trabalho concluído até o final de 2012.

\section{DISCUSSÃO}

Na figura 1 - elaborada a partir dos trabalhos selecionados - podemos observar que, de forma geral, houve um aumento da produção científica de dissertações e teses. Koski et al (2009) atribuem tal fato a maior profissionalização técnico-científica e ao aumento do número de programas de Pós Graduação Lato-Senso. 


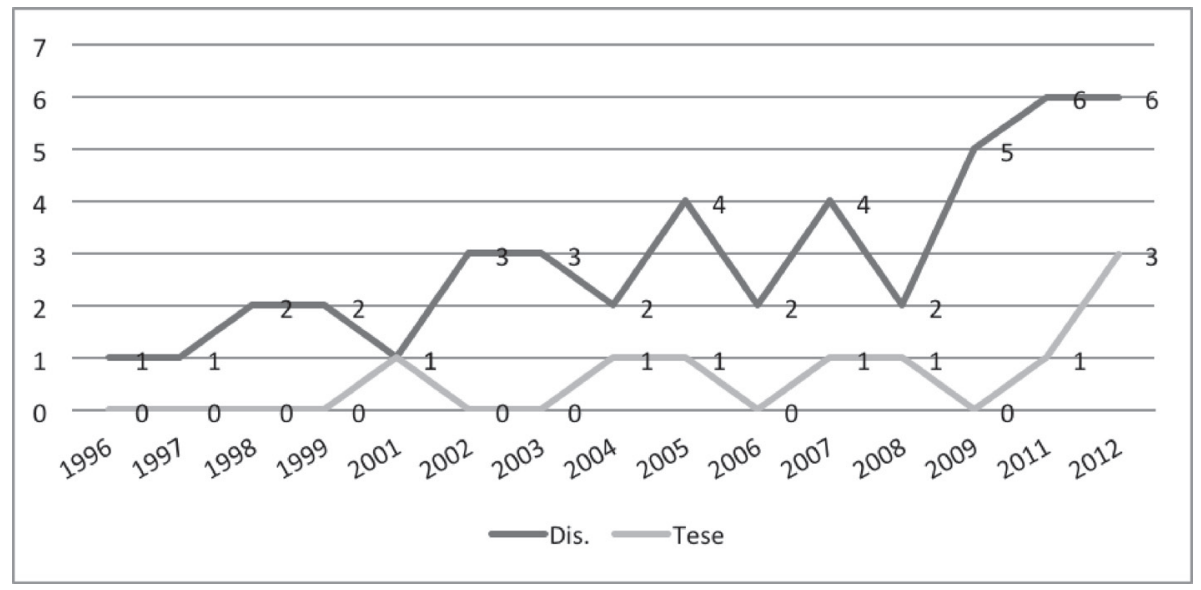

Figura 1 - Distribuição dos estudos sobre futsal publicados no período de 1996 a 2012 no banco de dados da CAPES. Fonte: Elaboração própria.

Podemos perceber que houveram avanços significativos na quantidade de dissertações e teses com relação à temática deste estudo. De fato, as produções de dissertações aumentaram sobretudo a partir de 2002, enquanto a produção de teses se deteve a uma, ou nenhuma por ano, chegando ao máximo de três produções em 2012.

Nos trabalhos qualitativos encontramos como principais instrumentos de coleta dos dados pelos pesquisadores entrevistas (15.1\% dos trabalhos), observações $(13,2 \%)$, questionários, filmagens $(11.3 \%)$ e análise de fontes impressas (1.8\%). Outra interpretação importante é que entrevistas, questionários e observações foram usados em conjunto como critério metodológico em três trabalhos (quadros 4 e 5). Nos trabalhos quantitativos aparecem a utilização de testes e protocolos específicos (30.1\%), avaliação antropométrica (13.2\%) e aplicação de questionários $(9.4 \%)$. Além de outros instrumentos como, por exemplo, filmagem, análise biomecânica e marcadores bioquímicos. Interessante destacar que questionários são utilizados tanto para pesquisas de caráter qualitativo quanto quantitativo. Esta prevalência pode ser explicada pelo fato de tal instrumento possuir baixo custo e fácil aplicação (GIL, 1995). Para Sampaio e Mancini (2007) estudos similares a esse, servem para identificar quais métodos são utilizados em uma determinada área.

Conforme demonstrado no quadro 8 , dos 53 trabalhos selecionados podemos dizer que de certa forma há um equilíbrio nas pesquisas relacionadas entre os assuntos preparação física, tática e pedagógica do esporte. Nesse sentido, faremos algumas considerações, tais como: $30,1 \%$ tratavam de assuntos fisiológicos, como limiar anaeróbio, dobras cutâneas, consumo de oxigênio (WILMORE, COSTILL, 2004); 22,6\% abordavam questões referentes a tática, o que 
para alguns autores envolvem as estratégias de jogo e treino usadas por técnicos e atletas do futsal (GARGANTA, 2001; SAAD, 2012); a prática pedagógica também prevaleceu em $22,6 \%$ das pesquisas, ou seja, os autores estavam preocupados principalmente com o lado educacional, ou pedagógico do esporte (FREIRE, 2006); 18,8\% tratam da preparação física em geral, isto é, os autores estavam preocupados com questões que analisem o desempenho, rendimento esportivo dos atletas, ou das equipes de futsal; $13,2 \%$ utilizavam a técnica do esporte, os fundamentos específicos do futsal para atingirem seus objetivos.

Constatamos poucos estudos com ênfase em determinados assuntos como, por exemplo, perfil dos praticantes do futsal $(5,6 \%)$, ou gênero $(7,5 \%)$. Verificamos maior incidência de estudos envolvendo atletas masculinos (49 estudos) em comparação aos femininos (quatro estudos). Isso pode ser explicado pelo fato de que somente recentemente a mulher passou a ser foco de pesquisas em diferentes esportes (DEVIDE et al., 2011). Notamos que não há uma preocupação com alguns assuntos, por exemplo, sobre os aspectos que tratam do futsal sob a perspectiva social do esporte.

\section{CONSIDERAÇÕES FINAIS}

Reconhecemos a necessidade de aprofundar esse estudo com outras bases de dados, sobretudo as relacionadas com artigos científicos, e posteriormente se faz necessário atualizar essa proposta de estudo, visto que o estudo se limitou a busca a partir de 1996 até o ano de 2012.
A necessidade de aprofundamento se dá, porque é possível perceber que houve avanços significativos nas produções referentes ao tema, bem como na diversidade de assuntos abordados.

Portanto, nessa análise, encontramos maior número de dissertações (44 trabalhos) quando comparado ao de teses (9 trabalhos). Foi possível perceber que tais trabalhos são predominantemente de caráter quantitativo em comparação com os qualitativos. Vale destacar que a partir do quadro 8, a intenção foi apontar os assuntos mais e menos abordados com relação ao esporte em questão. Os principais assuntos discutidos nas teses e dissertações são aspectos fisiológicos, tática e pedagógica do esporte. Por outro lado, assuntos como seleção e detecção de talentos e futsal enquanto disciplina acadêmica foram tratados em somente um trabalho cada $(1,8 \%)$. Certamente, nessa perspectiva, os trabalhos analisados não dão conta de responder algumas perguntas, tais como: como os jovens atletas deste esporte são selecionados? como o futsal é tratado enquanto disciplina acadêmica?

Portanto, podemos concluir de uma maneira geral, que os achados nesse estudo são relevantes para o campo acadêmico, especificamente para o contexto do futsal. Como principal legado deste estudo, apontarmos então, algumas lacunas na produção de dissertações e teses com relação aos assuntos identificados. Por exemplo, a iniciação esportiva, abordagens sociológicas e históricas do esporte, foram temas não abordados de forma central nos estudos de futsal, sobretudo das teses pesquisadas, ou seja, são pouco discutidos academicamente com relação ao esporte pesquisado. 


\section{REFERÊNCIAS}

DANTAS, P. M. S. Identificação dos perfis genético, de aptidão física e somatotípico que caracterizam atletas masculinos de alto rendimento, participantes do futsal adulto no Brasil. Dissertação (Mestrado em Sociologia). Universidade Castelo Branco, Rio de Janeiro, 2001.

DANTAS, P. M. S. Relação entre estado e predisposição genética no futsal brasileiro. Tese (Doutorado). Programa de Pós-graduação da Universidade Federal do Rio Grande do Norte, Natal, RN. 2004.

DEVIDE, F.P., OSBORNE, R., SILVA, E.R., FERREIRA, R.C., CLAIR, E.S., NERY, L. C. Estudos de gênero na Educação Física Brasileira. Motriz. Revista da Educação Física. 7 (1), 93-103. 2011.

FERREIRA, N. S. A. Pesquisa em leitura: um estudo dos resumos de dissertações de mestrado e teses de doutorado defendidas no Brasil, de 1980 a 1995. Campinas (SP): Faculdade de Educação, Universidade Estadual de Campinas, v. 139, 1999.

FERREIRA, N. S.A. As pesquisas denominadas "estado da arte". Educação \& Sociedade, São Paulo, ano 23, n.79, p. 257-272, ago. 2002.

FERREIRA, A. L. P. O estado da arte da sociologia do esporte no Brasil: um mapeamento da produção bibliográfica de 1997 a 2007. Dissertação (Mestrado em Sociologia). Universidade Federal do Paraná, Curitiba, 2009.

FIORENTINI, D. Rumos da pesquisa brasileira em educação matemática: $O$ caso da produção científica em cursos de pós-graduação. 1994.
FREIRE, J.B. Pedagogia do Futebol. Campinas, SP: Autores Associados. 2006.

GARGANTA J. A análise da performance nos jogos desportivos. Revisão acerca da análise do jogo. Revista Portuguesa de Ciências do Desporto. 1:57-64. 2001.

GIL, A.C. Como elaborar Projetos de Pesquisa. São Paulo; Editora Atlas S.A. 1995.

KOSKI, R.H. et al. A caracterização do esforço físico no futsal. RBFF-Revista Brasileira de Futsal e Futebol, v. 1, n. 2. 2009.

MEGID NETO, J. Tendências da pesquisa acadêmica sobre o ensino de ciências no nível fundamental. Campinas (SP): Faculdade de Educação, Universidade Estadual de Campinas, v. 238, 1999.

REZER, R. A prática pedagógica em escolinha de futebol/futsal: possíveis perspectivas de superação. Dissertação de Mestrado. UFSC. Educação Física. 2003.

RODRIGUES, F.X. F. A Formação do jogador de futebol no Sport Club Internacional (1997-2002). Dissertação (Mestrado em Sociologia) - Universidade Federal do Rio Grande do Sul, Porto Alegre. 2003. SAAD, M.A. A formação técnico-tática de jogadores de futsal nas categorias sub-13 e sub-15: análise do processo de ensino-aprendizagem-treinamento. Tese (doutorado) - Universidade Federal de Santa Catarina, Centro de Desportos, Programa de Pós-Graduação em Educação Física, Florianópolis, 2012.

SAMPAIO, R. F., MANCINI, M. C. Estudos de revisão sistemática: Um guia para síntese criteriosa da evidência científica. Revista Brasileira de Fisioterapia, 11, 83-89. 2007. 
SANTANA W. C. Futsal: metodologia da participação. Londrina: Lido, 1996.

SANTANA W. C. A pedagogia do esporte e a moralidade infantil. 2003. Dissertação (Mestrado em Educação Física) - Faculdade de Educação Física, Universidade Estadual de Campinas, Campinas, SP, 2003.

SANTANA, W. C. A Visão Estratégico-

Tática de Técnicos Campeões da Liga Nacional de Futsal. Tese (Doutorado em Educação Física) - Faculdade de Educação Física. Universidade Estadual de Campinas, Campinas, 2008.
SILVEIRA, S.; STIGGER, M. P. Jogando com as feminilidades: um estudo etnográfico em um time de futsal feminino de Porto Alegre. Rev. Bras. Ciênc. Esporte, Florianópolis, v. 35, n. 1, p. 179-194, jan./mar. 2013.

SOARES, M. B. Alfabetização no Brasil: o estado do conhecimento. Instituto Nacional de Estudos e Pesquisas Educacionais, Reduc, 1989.

WILMORE, J. H., COSTILL, D. L. Physiology of sport and exercise. Champaign, IL: Human Kinetics. 2004.

SCIENTIFIC PRODUCTION ON FUTSAL: analysis of dissertations and theses published in the portal Capes between 1996-2012

\section{ABSTRACT}

The present study investigated through an analysis of the dissertations and theses in gifts of Capes Portal site, which discusses the context of futsal, as well as highlighting the objectives of these studies, methodologies, trace similarities, differences and notes for possible future productions. To collect use the search field Subject to the term "futsal". 53 studies were selected and verified predominance of dissertations (83\%) in relation to theses $(17 \%)$. The surveys are mostly of quantitative nature $(59.3 \%)$ compared to qualitative $(36.7 \%)$ and quantitative / qualitative $(4 \%)$. They are referenced as a case study, field research, ethnographic research, descriptive and quasi-experimental. As for the methodological procedures were used questionnaires, interviews, observations, filming, specific protocols and testing applications. With the issues discussed in the selected work, we identified most of them use the futsal to address the physiological aspects (30\%) and tactical (19\%) of the sport. In this sense we note that there is a concern in studying certain subjects in the mode searched, for example, no research discusses the futsal through a social approach this sport. We conclude that this may be considered a gap in the academic field of sport and searched it is necessary to exploit it.

Keywords: Futsal Academic Production; Vocational Training. 
PRODUCCIÓN CIENTÍFICA EN FÚTBOL SALA: análisis de disertaciones y tesis publicadas en el portal CAPES entre 1996-2012

\section{RESUMEN}

Este estudio investigó a través de un análisis en disertaciones y tesis presentes en el sitio Portal Capes, que cubre el nivel de fútbol sala, así como poner de relieve los objetivos de estos estudios, las metodologías, trazar similitudes, diferencias y posibles notas para futuras producciones. Para recoger el uso del campo de búsqueda Sujeto al término "fútbol". Se seleccionaron 53 estudios y verificados predominio de disertaciones $(83 \%)$ en relación a las tesis (17\%). Las encuestas son en su mayoría de carácter cuantitativo (59.3\%) en comparación con el cualitativo $(36.7 \%)$ y cuantitativa / cualitativa (4\%). Ellos son referenciados como caso de estudio, investigación de campo, la investigación etnográfica, descriptivo y cuasi-experimental. En cuanto a los procedimientos metodológicos se utilizaron cuestionarios, entrevistas, observaciones, el rodaje, protocolos específicos y aplicaciones de prueba. Con los temas discutidos en la obra seleccionada, se identificaron más de ellos utilizan el fútbol sala para abordar los aspectos fisiológicos (30\%) y táctica (19\%) de este deporte. En este sentido observamos que existe una preocupación en el estudio de ciertos temas en el modo buscado, por ejemplo, ninguna investigación analiza el fútbol sala a través de un enfoque social de este deporte. Llegamos a la conclusión de que esto puede ser considerado como un vacío en el campo académico de deporte y buscó hay que explotarlo. Profesional.

Palabras claves: Fútbol Sala; Producción Académica; Formación Profesional

Recebido em: março/2015

Aprovado em: agosto/2015 